\title{
Military Readiness and Environmental Protection through Cost-effective Land Conservation
}

Kent D. Messer, Maik Kecinski, Zhuo Liu, Mary A. Korch, and Thomas Bounds

We regret our error in our article published in Land Economics volume 92, issue 3,
August 2016, pages 433-49. Author Zhuo Liu's name was misspelled as Zhou Liu. 